\title{
Generic Strategy and Strategic Management Accounting Practices: Case Study of a Sri Lankan Telecommunications Company
}

\author{
H. Rathwatta \\ University of Sri Jayewardenepura \\ D. N. Samudrage \\ University of Sri Jayewardenepura
}

\begin{abstract}
Organizations depend on different generic strategies to gain competitive advantage (Porter, 1980). Usage of a particular generic strategy is always associated with a set of rules, practices, and procedures within an organization. Amongst them, Strategic Management Accounting (SMA) practices play a vital role in supporting and monitoring the performance of the generic strategy pursued by an organization. However, organizations may change the generic strategies they use over the time due to various changes taking place in the environment including the changes in business environment, technology, competitors, regulation and the global economy (Wickramasinghe \& Alawattage, 2007). A change in the strategy is expected to lead to changes in existing policies and practices to match the new strategy (LangfieldSmith, 2007). Thus, SMA practices used by the organization should be no exception. Such changes in practices are important for effective implementation of the new strategy. Otherwise, the new strategy is expected to fail. However, studies, which examine the changes in generic strategy and associated changes in SMA practices are scarce in the Sri Lankan context. Hence, the purpose of this paper is to examine whether the change in generic strategy leads to changes in SMA practices used in Alpha Telecom PLC, which is a leading telecommunications company in Sri Lanka.
\end{abstract}

\section{Corresponding Author:}

H. Rathwatta, University of Sri Jayewardenepura, E-mail: hrathwatta@gmail.com 
Also, the study expects to find out other factors contributing to the changes in SMA practices in this company.

This study adopted the qualitative research methodology and used the single case study method to conduct an in depth analysis of SMA practices of Alpha Telecom. The data were collected through semi-structured interviews with senior managers and a questionnaire was distributed among middle level executives. Management Accounting (MA) reports and annual reports of the company were used as secondary sources. The study has used new institutional theory as the theoretical lens. The study found that when generic strategy moved from cost leadership to differentiation, the traditional MA practices based on costing shifted to SMA practices such as Balanced scorecard (BSC), Competitor analysis, Quality costing etc. Further, it was found that changes in ownership, culture of parent company, and nature of competition also had an impact towards the usage of new SMA practices within the company. Coercive and mimetic pressures affected for the usage of SMA at Alpha PLC.

\section{Keywords}

Strategic Management Accounting Practices; Generic Strategy; Differentiation; Cost Leadership; New Institutional Theory

\section{Introduction}

Considering the rise in competition within the corporate world, as an effect of globalization and development of technology the success or failure of any business depends on developing and maintaining a Sustainable Competitive Advantage. This crucial factor is now considered as the heart of a company's performance and survival in the ever-changing market. After several decades of vigorous expansion and growth, many firms lose sight of this key component during their scramble and pursuit for growth, expansion, and even diversification. Today, a company's continuous focus on gaining a competitive advantage could hardly be greater than any other concerns it faces. The firms are using generic strategies (Porter, 1985) to gain competitive advantage. The main generic strategies are cost leadership, differentiation, and focus. The generic strategy of the business may be changed due 
to the changes in business environment, technology, competitors, regulations and the global economy (Wickramasinghe \& Alawattage, 2007). Further there is significant relationship between Management Accounting (MA) and business strategies (Simmonds, 1981). MA practices are developed from traditional aspects to strategic aspects due to the changes in external environment and internal environment (Burns \& Scapens, 2000). Hence a new MA discipline has been coined by Simmonds (1981) and defined it as "The provision and analysis of management accounting data about a business and its competitors, for use in developing and monitoring business strategy" (Simmonds, 1981, p. 26). Roslender and Hart (2003, p. 272) defined that SMA is about making MA more strategic. However, Langfield Smith (2008) stated that there is no agreed definition of SMA in the literature and recognized SMA as accounting information about competitors, suppliers, and customers. Further, Nixon and Burns (2012) pointed out that Simmonds (1981) has developed the concept SMA by considering the generic strategies of Porter (1980). Hence the firms practice SMA techniques rather than traditional MA to provide more strategic information for strategy formulation. Most prior studies have paid more attention on 'what' are the SMA techniques used in different firms in different contexts (Guildings, 1999, Guilding, Cravens \& Tayles, 2000; Cravens \& Guilding, 2001; Guilding \& McManus, 2002; Langfield-Smith, 2008; Nixon \& Burns, 2012; Abdullah \& Said, 2015). Few studies have been conducted to examine the relationship between SMA practices and competitive advantage (Rickwood, Coatest and Staceyt, 1990; Cinquini \& Tenucci, 2010). These studies also haven't focused on why do SMA practices change with competitive advantage and how do the firms adopt SMA techniques to gain competitive advantage. Further, Tillmann and Goddard (2008) stated that the practice of SMA is different in each firm, each country and each context. Considering the available literature this paper addresses the following research questions;

- How do SMA practices change with generic strategy in a telecommunications company in the Sri Lankan context?

- Why do firms adopt SMA practices with generic strategy?

The study aims to examine whether the change in generic strategy leads to changes in SMA practices in a selected telecommunications company in Sri Lankan context in a new institutional perspective. The eleven SMA practices (under cost perspective, customer perspective, competitor perspective and performance perspective) used by Cinquini and Tenucci (2010) are applied for the current study to identify SMA practices.

The findings of the study generate a valuable insight to the SMA literature as little is known in the discipline of SMA. Further, Nixon and Burns (2012) suggested 
conducting more studies in this discipline as there is a lacuna in the SMA literature. The findings generate a sound contribution to SMA research studies in the Sri Lankan context as Langfield-Smith (2007) suggested conducting studies on practice of SMA techniques in specific organizational contexts. Further, the current study generates valuable insight on using new institutional theory in MA research. In addition to the above, there is considerable relevance of the findings towards to practical usage as managers can learn how to use SMA techniques as a strategic information tool for crafting strategies and deciding their generic strategy to gain competitive advantage.

The paper is organized as follows: the first section gives a brief review of SMA practices, generic strategy and prior studies on business strategy and SMA. The next section explains the case unit (Alpha Telecom PLC) and the research methodology. Subsequently, research findings and discussion are explained. The final section is dedicated to explain the conclusions of the study.

\section{Literature Review}

This chapter will first present the definitions of SMA followed by the definitions on Generic Strategies. Then, the prior studies on Business Strategies and SMA practices are elaborated.

\section{Strategic Management Accounting (SMA) Practices}

Simmonds (1981) first introduced the term Strategic Management Accounting, outlining it as the provision and analysis of management accounting data about a business and its competitors, for use in developing and monitoring business strategy. Bromwish (1990) defined SMA from a financial perspective as the provision and analysis of financial information on the firm's product markets and competitors' costs and cost structures and the monitoring of the enterprise's strategies and those of its competitors in these markets over a number of periods. Bromwich and Bhimani (1994) stated that SMA requires accountants embrace new skills beyond their usual abilities and co-operate more with general management, corporate strategies, marketing and product development. Coad (1996) stated that SMA is an emerging field, whose boundaries are loose and yet, there is no unified view of what it is or how it might develop. Brouther and Roozen (1999) argued that SMA provides information on environmental analysis, strategic alternative generation, strategic alternative selection, planning the strategic implementation, implementing the strategic plan and controlling the strategic management process. According to them, strategic management information is mostly non-financial and future focused. The Chartered Institute of Management Accountants in UK (2005) 
stated SMA as "A form of management accounting in which emphasis is placed on information which relates to factors external to the firm, as well as non-financial information and internally generated information". Roslender and Hart (2002) stated that SMA's defining characteristic is the MA interface with marketing management rather than strategy. However, in the accounting literature, there is no agreed definition of SMA (Langfield-Smith, 2008). This study has used the SMA techniques, which are used by Cinquini and Tenucci (2010).

Table 1: SMA techniques from the literature

\begin{tabular}{ll}
\hline Category of SMA Technique & SMA Techniques \\
\hline Costing & Activity Based Costing (ABC) \\
& Life cycle costing \\
& Quality costing \\
& Target costing \\
& Value chain costing \\
& Customer Analysis (CA) \\
Customer & Competitive position monitoring \\
Competitor & Competitor Cost Assessment \\
& Competitor Performance Appraisal based on \\
& Public Financial Statements \\
Performance & Benchmarking \\
& Balanced Scorecard (BSC) \\
\hline
\end{tabular}

Source: Cinquini, L. and Tenucci, A. (2010)

\section{Generic Strategy}

According to Porter (1985), Competitive Advantage is the attribute that allows an organization to outperform its competitors. This concept aims to build a strong relationship between strategy formulation and implementation. Further, it supports to establish a profitable and sustainable position against the forces that determine industry competition. Porter (1985) defined two ways in which an organization can achieve competitive advantage over its rivals: cost advantage and differentiation advantage. The two basic types of competitive advantage combined with the scope of activities and form four strategies called 'Generic Strategies'. They are Cost Leadership, Differentiation, Cost Focus and Differentiation focus. The cost leadership and differentiation strategies seek competitive advantage in a broad range of industry segments while focus strategies aim at cost advantage (cost focus) or differentiation (differentiation focus) in a narrow segment. This study is focusing only on cost leadership and differentiation. Cost leadership is a business' ability to produce a product or service that will be at a lower cost than that of other 
competitors. A differential advantage is the ability to differentiate its products or services from competitors (Porter, 1985).

Figure 1: Generic Strategies for Competitive Advantage by Porter (1985)

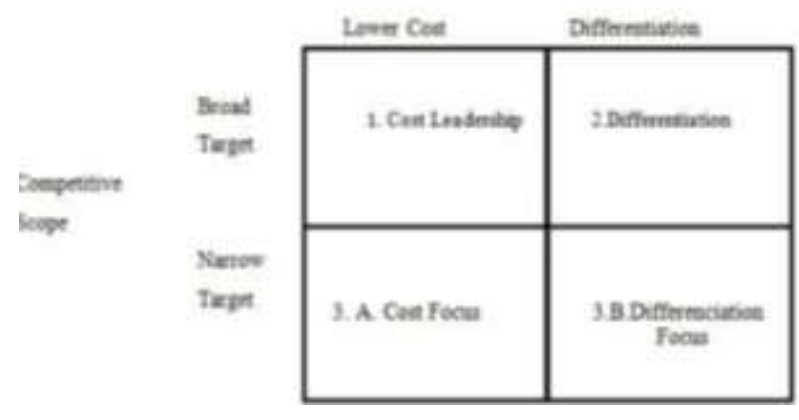

Source; Porter, M. (1985), "Competitive Advantage”

\section{Prior Studies on SMA}

Simmonds (1981) stated that Management accountants could assess the strategic impact of internal information and collect information about the position of competitors. Shank (1989) stressed the need for MA to support a firm's competitive strategies and illustrated how these different MA techniques support different competitive strategies such as cost leadership and product differentiation. Using Porter's taxonomy, Shank (1989) and Shank and Govindarajan (1989) analyzed the relative importance of several MA methods depending on whether the firm was pursuing cost leadership or differentiation. They conveyed that companies choosing cost leadership would put the most emphasis on the traditional cost accounting applications. Simons (1990) investigated the role of management control systems (MCS) in creating competitive advantage and he has used strategic models of Miles \& Snow (Defender, Prospector, Analyzer, Reactor), Mintzberg (Entrepreneurial, Adaptive, Planning mode), Porter (Cost leadership, Differentiation, Focus). The analysis showed that interactive management control processes can be used to manage emergent strategy, rather than focusing on what the organization already understands and does well, these systems direct organizational attention to emerging threats and opportunities. Rick wood, Coatest and Staceyt (1990) carried a case study to investigate SMA to gain competitive advantage and they pointed out that it is desirable to release MA from the factory floor to allow it to also aid directly new market challenges. Lord (1996) identified a specific characteristic of SMA. He stated that firm can gain competitive advantage by using SMA techniques which are analyzing a way to decrease costs and enhance the differentiation of a firm's product, through exploiting linkages in the value chain and optimizing cost drivers. 
Chenhall and Langfield- Smith (1998) examined the relationship between strategic priorities, management techniques, and MA. Their results showed that high performing product differentiators are associated with MA techniques of quality systems, integrated systems, team-based human resource structures and MA practices incorporating employee-based measures, benchmarking, strategic planning techniques and activity-based techniques. On the other hand, high performing lowcost strategy firms are associated with MA techniques of improving existing processes, integrating systems, innovating manufacturing systems and activitybased MA techniques. Guilding, Cravens and Tayles (2000) carried out an international comparison of SMA practices to identify the usage of SMA in New Zealand (NZ), United Kingdom (UK), and the United States of America (USA). They used 12 SMA techniques. These are attribute costing; brand value budgeting and monitoring, competitor cost assessment, competitive position monitoring, competitor appraisal based on published financial statements, life cycle costing, quality costing, strategic costing, strategic pricing, target costing and value chain costing. Competitor accounting and strategic pricing appears to be the most popular SMA practice in three countries. Target costing is highly used in NZ and U.S. Further, Companies in NZ and UK make greater use of value chain costing, competitive position monitoring, and competitor performance appraisal based on published financial statements while the U.S. uses them to a relatively low degree. NZ companies showed a great tendency for SMA. Finally, they found that there is negligible use of the term 'SMA' in organizations. Cravens and Guilding (2001) pointed out that there are significant relationships between SMA usage and competitive strategy by considering research and development and market coverage aspects. Roslender and Hart (2002) stated SMA as the interface between marketing and MA to pursue competitive advantage through market positioning strategies. Wickramasinghe and Alawattage (2007) stated that MA is influenced by environmental factors such as technology, competition, global effects, economic uncertainty, social and cultural influences and political influences. Further they have mentioned SMA can be used to gain sustainable competitive advantage via strategic market position. Cadez and Guilding (2008) carried out an investigation of an integrated contingency model of SMA. 16 SMA techniques have been identified for analysis in this study based on sub categories (costing, planning, control and performance measurement, decision-making, competitor accounting and customer accounting). They found that accountants' participation in strategic decision making is positively associated with prospector strategy. Tillmann and Goddard (2008) conducted a qualitative study in a large multinational company in Germany to investigate how SMA is perceived and used in practice from a grounded theory perspective. The study found that external and internal contexts affect management accountants in using SMA to understand the different situations in strategic aspect. 
Cinquini and Tenucci (2010) carried out a study to identify whether business strategy influences SMA usage. They stated that competitor analysis, competitive position monitoring, competitor performance appraisal based on published financial statements and quality costing are widely used in Italian companies. Further, they have stressed that differentiators are more interested in SMA techniques to address customer, competitor, and performance information. Cost leaders are interested in SMA techniques based on cost information. Lachmann, Knauer and Trapp (2013) conducted a study to examine the dissemination of SMA techniques in hospitals under competitive market environments. They stated that a firm's structure and ownership affects the usage of SMA techniques as publicly owned hospitals are more interested in cost and risk based SMA techniques. Abdullah and Said (2015) have stated that SMA techniques provide information about competitive strategy, firm development, market changes, and corporate strategic program, strategic implementation and strategic control.

\section{Theoretical Lenses}

\section{Institutional Theory in MA}

The study used new institutional social theory as the theoretical lens. Meyer and Rowan (1977) firstly discussed the institutional theory by mentioning that the organizations are driven to implement practices and procedures to rationalize the concepts of organizational work and institutionalized in the society to enhance their legitimacy and survival and Meyer and Rowan (1977) defined institutionalization as the processes by which social processes, obligations, or actualities come to take on a rule like status in social thought and action (pp 341). The relationship between organizational practices and the society is elaborated in the process of isomorphism (DiMaggio and Powell, 1983). Hawley (1968) defined isomorphism is as a constraining process that forces one unit in a population to resemble other units that face the same set of environmental conditions (as cited DiMaggio \& Powell,1983). Further, DiMaggio and Powell (1983) have identified three mechanisms that affect institutional isomorphic change. They are coercive (the formal and informal pressures exerted on organizations from cultural expectations of the society), mimetic (the way organizations model themselves on other organizations to face uncertainty in the environment) and normative (the way organizations act like others in the field because of social and cultural pressures to establish occupational autonomy). Hence intra-organizational structures and procedures are largely shaped by external institutions which consist of cognitive, normative and regulative structures (Gamage \& Gooneratne ,2017).

Hoque and Alam (1999) conducted a case study to explore the changes in management accounting systems (MAS) aligned with TQM in a New Zealand 
construction company and found that MAS are changed due to external pressure and achieve external legitimacy. Sharma and Hoque (2002) also studied the implementation of TQM in a Housing Authority in Fiji. According to institutional perspective, they mentioned that the organizational survival requests conforming to social norms and the selected case company implemented TQM to achieve external legitimacy. Siti-Nabiha and Scapens (2005) have applied Old Institutional Economics and New Institutional Sociology to explore the relationship between stability and change with the process of accounting change. Further, they mentioned that the interaction of internal and external institutions shaped the MA changes in the firm. Youssef (2013) has stated that external factors such as global competition, recession in the country affect management accounting change in the perspective of old institutional economic theory, referring to an Egyptian organization. Cadez and Gooneratne (2016) studied the reasons for the implementation of ABC in a Sri Lankan Manufacturing firm. They have referred to Old Institutional Economics theory to explain the finding in a theoretical perspective and they mentioned that $\mathrm{ABC}$ is implemented in the selected firm ceremonially and instrumentally. Gooneratne and Hoque (2016) pinpointed that external institutional forces and organizational entrepreneurs are strongly affected the institutionalization of the budgeting system in a Sri Lankan hybrid state-owned entity due to pressure of a competitive environment and economy.

\section{New Institutional Sociology (NIS) theory in MA}

Tsamenyi, Cullen and Gonzalez (2006) carried out a case study to investigate the changes in the accounting and financial information system of a large Spanish electricity company and they found that coercive pressure from both regulatory environment and head office control and normative pressure from professional groups influence the changes in accounting and financial information system. Hopper and Major (2007) stressed that ABC is implemented in a Portuguese Telecommunications company to improve the competitiveness and efficiency logic with the influence of mimetic, coercive and normative factors in new institutional theory. Gamage and Gooneratne (2017) explored how management controls change according to the external institutional forces and the internal dynamics in an apparel firm in Sri Lanka and they pinpointed that coercive, normative and mimetic pressures in the environment affect management control changes. Kapiyangoda and Gooneratne (2018) conducted a study to explore how management control systems of a firm is affected by the parent companies' culture and the study has used institutional theory as the theoretical lens. They have identified the rules and procedures applied by the parent company to case company as coercive isomorphism. Arroyo (2012) suggested a new perspective of institutional theory called institutional entrepreneurship to bridge the gap between old institutional 
economics and new institutional sociology to study how new MA practices are socially constructed.

\section{Case Study Company}

Alpha Telecom PLC (hereafter referred to as Alpha) is a key player in the telecommunications industry in Sri Lanka. Initially it started as a government owned organizations in 1980 and is presently owned by a Netherlands company. Alpha is more strategic oriented as there is a vigorous competition in the telecommunications industry. It was operated with lots of red tape when Alpha was under government ownership. Considering the emerging competition in the industry, the government decided to privatize the firm. Then, Alpha was acquired by a Japanese company for five years. In 2003, Alpha became a public limited company. In 2008, the ownership of the Japanese company was sold to a Netherlands company. Currently, The Chairman of the company is appointed by the Government and the Chief Executive Officer (CEO) is appointed by the Netherlands ownership. Alpha is operating as a group of companies, which includes ten subsidiaries in telecommunications infrastructure, mobile communication, broadband, human resource management, etc. Currently Alpha provides services in voice, data, broadband, wholesale, enterprise, cloud, international and TV.

In 1993, a French consultation company developed a strategic plan for Alpha. But it did not succeed due to political influences. Then, in 1997, the Japanese management developed a strategic plan with a new vision and a mission, which were more cost and technical oriented. There had been a highly hierarchical organization structure until privatization. The structure was clearly static. After the privatization, the Japanese management introduced an expanded structure. Further, the Japanese management identified the need for customer care. They opened flag ships for customer care and organized many training programmes island wide for customer care. After that the Netherlands management changed the existing vision and mission which is aligned with customer and competition aspects. The Netherlands management has also implemented some changes in the structure based on their transformation program by adding new positions to suit market orientation and customer focus. Further, they have established a committee called "Customer Complaint Committee" to solve customer complaints.

Before privatization there were few accounting and financial activities. The accounting process was carried out manually. After the Japanese Management took over the management, they introduced a computer based accounting system in 2000 which generated financial statements. Thereafter Alpha became a public quoted company, it was mandatory for them to provide quarterly and annual reports to the 
Colombo Stock Exchange. Further, the Japanese management introduced new MCS such as $5 \mathrm{~S}$, Kaizen, and cross functional teams into the system.

\section{Research Methodology}

This study has adapted the qualitative research methodology and used single case study method (Yin, 2003) to conduct in depth analysis of SMA practices of Alpha. As Denzin and Lincoln (2000) mentioned qualitative studies are conducted to find the answer for how social experience is created and given meaning. Yin (2009) further elaborated that the case study method addresses the "how" or "why" questions in any context. Even the base research paper (Cinquini and Tenucci, 2010) suggests carrying out the case study method to understand the process of adaptation and use of SMA. Hence, Alpha was selected as the case unit because it has been managed by different companies with different strategic intentions and the main objective of the study is to conduct an in depth analysis of SMA practices of Alpha.

During the data gathering process, primary and secondary data were collected through several sources. Primary data were mainly collected from interviews with top and middle level managers. Interviews were carried out with the Deputy Chief Corporate Officer, Deputy General Managers and Senior Executives in Marketing, Customer Services, Procurement Divisions, Finance, Quality Assurance Division and Project Management Division. There were fifteen in-depth interviews carried out covering the related departments with SMA practices. All the interviews were semi-structured interviews and based on a pre-set interview protocol. The interview protocol was updated as the interviews progressed from one person to the other person. Interviews were limited to a maximum of one-and-half hours and certain executives could be followed up for more details. In addition to face to face interviews, data were gathered through several follow-up telephone interviews. All the interviews were voice recorded with the permission of the respective interviewees. These voice records were subsequently transcribed. Further a survey questionnaire was distributed among fifty middle level executives to verify the findings of the interviews. As secondary sources the company web site, MA reports, annual reports of the company, published articles of Alpha were studied in detail.

The analysis of data was carried out based on thematic analysis of Braun and Clarke (2013). Accordingly, the conducted interviews were transcribed into the notes. Then the transcribed notes of interviews and documents were analyzed to identify the answers for the research questions. The researchers used both interviews and the questionnaire survey method to enhance validity and reliability through methodological triangulation. 


\section{Findings and Discussion}

\section{Evolution of Management Accounting practice in Alpha}

The origin of accounting practice of Alpha was a legacy of colonial relationships. They followed financial accounting practices in the early stages in keeping with the state regulations and the accounting environment was highly bureaucratic. The management did not pay attention to customer satisfaction, quality of service, and market conditions. A senior manager stated the reason for the above narrow practice of accounting,

"The strategic direction and focus were different because there was no competition. We enjoyed a monopoly situation"

When Alpha Telecom was acquired by a Japanese company, the accounting practices were expanded to MA. A senior manager stated:

"Gradually the Japanese management developed the infrastructure of the company and changed the attitudes of employees. They eliminated the red tape. They were interested much in MA and control systems"

A comment of a senior executive in the accounting division implied that MA practice was started during the Japanese management period.

"Around 2000, we developed MA practice in relation to Japanese management. During this period, MA practice was in its initial stage. Now it is advanced and its quality is high"

The interest in MA was increased after the Netherlands management took control as they see more on the marketing perspective. A senior manager supported:

"Netherlands management is interested in management accounting a lot. They demand reports like cost analysis, revenue analysis, segment analysis and monthly performance reviews etc."

The Netherlands management has changed the organizational structure. Preparation of MA is assigned to a new department called "Finance Planning" and Budgeting is under the Assets Management division. Further some MA related reports are produced by other departments such as Marketing, Quality Assurance, and Projects etc. 
The hierarchy of finance division under the Netherlands management was as shown below,

\section{Figure 2: Hierarchy of Finance Division}

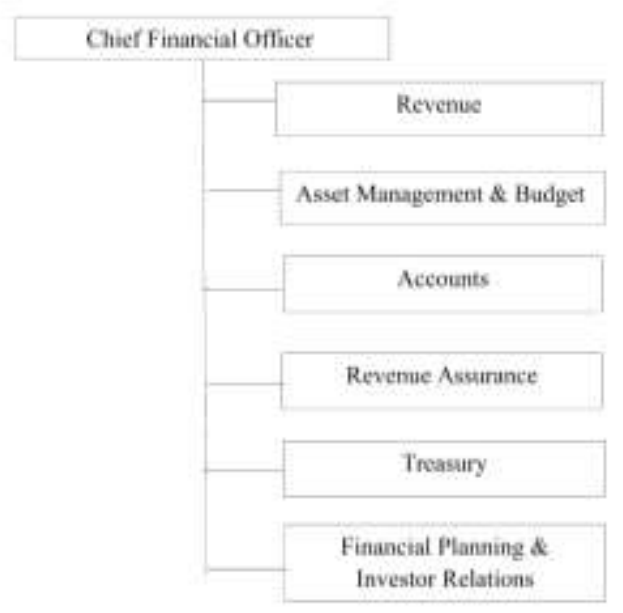

According to the survey conducted, there has been a high pace of development of MA during the period of the Netherlands management as the questionnaire respondents also supported the finding at $72 \%$ rate. Strategic Management Accounting practices at Alpha referring the same identification used by Cinquini and Tenucci (2010).

Around 2008, Activity Based Costing (ABC) was introduced to the firm. They tried to use it for new product cost calculation. But it did not succeed. A senior corporate officer commented that:

"The management tried to introduce $\mathrm{ABC}$. But they were unable to implement it properly"

Hence the ABC method is still in the initial stage. But they want to enhance the usage of it. They used $A B C$ to identify cost for new products and in the planning stage of products. Life cycle costing is not being used by the finance department. But the marketing department uses it for identification of costs of new products at different stages. Then, corporate department also uses this technique to decide strategies on products based on life cycle. Hence life cycle costing is being used by Alpha but it is not widely adopted. The quality costing practice is under the quality assurance department. The quality costing is based on continuous improvement, which was introduced by the Japanese management. This technique was more heavily used in the time of the Japanese management than the Netherlands 
management. Alpha pays considerable attention to quality costing as they are awarded with quality management awards such as ISO certificate. But they didn't disclose the process of preparing the quality costing. In Alpha, they use similar cost allocation methods to target costing in the project division to a certain extent. But they are not familiar with target costing. Alpha is not practicing value chain costing. But their pricing strategies are based on the value adding concept.

Multinational corporations, Small medium entrepreneurs, and domestic users are the main customers of Alpha. The Marketing division identified revenue generation and the cost incurred for each customer. Even the quality department mentioned that they are identifying the customer satisfaction and recording it. A corporate officer stated that corporate division prepares and uses customer analysis based on situations. It conveyed that Alpha is preparing customer analysis in three departments separately based on their special requirements. The marketing department of Alpha is preparing competitor position monitoring report monthly. This is directly sent to the CEO and called as "market situation report". Further they prepare a weekly report on market position which is called "Market Intelligence report". The competitor performance report based on financial reports is prepared by the financial department. This report is prepared to compare revenue and cost items with competitors. A senior manager in the marketing division stated that:

"Our finance division is doing a comparison of financial statements of our main competitor. But monthly statement is compulsory. In our monthly report, there is a section called "market situation report" under it there are two sections as customer analysis and competitor analysis"

Balanced scorecard (BSC) was introduced to Alpha by the Netherlands management. Hence it is at initial stage. The senior management tries to apply BSC in every department. Currently it is used by Corporate, Finance Human Resource, and Marketing Departments.

Table 2: Findings of questionnaire survey among executive staff

\begin{tabular}{llc}
\hline SMA Perspective & SMA Technique & Usage \\
\hline Cost & Activity Based Costing & Low \\
& Life cycle costing & Low \\
& Quality Costing & Average \\
& Target costing & Average \\
& Value chain costing & Low \\
& Customer Analysis & High \\
Customer & (CA) & \\
\hline
\end{tabular}




\begin{tabular}{lll}
\hline Competitor & $\begin{array}{l}\text { Competitive position } \\
\text { monitoring }\end{array}$ & High \\
& Competitor Cost & Low \\
& Assessment & \\
& Competitor & High \\
& Performance Appraisal & \\
based on Public & \\
& Financial & \\
Statements & Low \\
Penchmarking & High \\
\hline
\end{tabular}

Source: Survey data

According to the questionnaire survey among the executive staff, itt also proved that Alpha highly practices customer analysis, competitor position monitoring, competitor performance appraisal based on public financial statements and BSC. Further they practice $\mathrm{ABC}$ and quality costing to a certain extent. Survey findings also confirmed the interview findings that life cycle costing, target costing, value chain costing, competitor cost assessment and benchmarking are not familiar to Alpha.

\section{The Relationship between Competitive Advantage and SMA Practices}

\section{Under Government Ownership (before 1997):}

During the period under government control the main objective of Alpha was social welfare. Alpha was the only telecommunications provider and they had monopolistic power. Hence Alpha was not aware of competitive advantage. Few investors came to the market in the early 90's. But Alpha was able to maintain their monopoly due to the ownership structure. They kept accounts to identify revenue of government. Further, Alpha was not concerned about competitive advantage. Hence the management was not interested in MA techniques and MCS at that time.

\section{Under Japanese Management (1998-2007):}

After the privatization, the objective was changed. The profit maximization came into the stage. Effectiveness and efficiency became important. The Japanese management was futuristic and strategically focused. From time to time new telecommunications firms entered the telecommunications industry and created competition. The customers were becoming powerful as they got alternative companies other than Alpha. So, Alpha identified "customer satisfaction" as an important concept. They positioned their service in the competitive market as a 
"reliable service" because of the remaining government ownership with reasonable price. They used both the low cost strategy and differentiation strategy in different services to gain competitive advantage. International direct dialing (IDD) was based on a low price strategy. The wireless phone service was based on differentiation through technology and reliability of the service. When demand for fixed phone service went down due to mobile service, Alpha went for a low priced strategy for fixed phones offering different payment plans and services. They differentiated their services from "quality and advanced technology". The Japanese management was interested at a -MA in higher degree level and they established new division for MA under CFO. They used MA techniques to achieve their objectives of cost reductions, quality improvement, and customer satisfaction. Most of the MA techniques used during that time were based on cost. But they were concerned about customers and competitors. It is evident that during this period Alpha was using mainly MA practices introduced by the Japanese management.

\section{Under the Netherlands Management (2008-Present):}

In 2008, Alpha introduced a new service package in mobile service through its subsidiary. The new package targeted government employees with a low price plan. In 2010 the situation was changed as the Telecommunications Regulation Commission (TRC) implemented regulations on price strategies. Hence low-price strategy became unusable. In 2009, there was a transformation program in Alpha and they changed their vision and mission based on new strategic focus. The strategic focus was "customer centric and market oriented". The generic strategies for gaining competitive advantage also depended on their strategic focus. Alpha has 4 main products. They are Wire line fixed service, IDD, wireless fixed line phone, mobile service, and broad brand. Alpha uses lower priced for IDD as their technology is highly advanced and enjoys economics of scale. Alpha offered "a bunch of services" through combination of wire line with broadband service and has differentiated their service from others. A senior executive commented that:

"The way of presenting our broadband facility is now unique. We provide our fixed line connection with broadband service. It is a bundle of different requirements of the public. Our strategy is differentiation"

Alpha has been moving forwards from conventional MA to SMA practices. They have been measuring quality of services through MA practices. The customer satisfaction is also measured from the time of the Japanese management. These practices are being improved. Around 2008, Alpha started to practice competitor performance analysis using annual reports, when a main competitor entered into the Colombo stock exchange. Alpha uses competitor position analysis, Competitor 
performance analysis in significant stage, the life cycle accounting is also practiced to a small extent in the marketing and project divisions. Alpha is trying to implement $\mathrm{ABC}$ and $\mathrm{BSC}$ because its strategic focus changed. As the competition is increased, the environment of telecommunications industry becomes more dynamic. Alpha changed its strategic focus to survive in this dynamic environment. Based on that, they are interested in SMA practices. A senior executive said that:

"In 2000 it was not so important, because at that time as we were the market leader. But now there is a huge competition. We have to consider cost, quality. We can't just go for low cost end or high quality. We have to craft strategies by scanning the dynamic environment. So, we need more information. That is why there is a big demand for MA and control systems"

In summary, the findings of the study convey that traditional MA techniques are expanded to SMA due to change of generic strategy from cost leadership to differentiation as the dynamic business environment changed. The business environment has converted to a more challengeable due to vigorous competition, high bargaining customers, and government regulations compared to the early days of Alpha. These changes force them to move from cost leadership to differentiation. The need for external oriented information is gradually increased with strategic change. Therefore traditional MA practices have been shifted to SMA based not only on cost perspective but also on the customer, competitor, and performance perspectives.

The study examined the usage of SMA techniques with the changes of generic strategy in a case company in Sri Lanka. The findings elaborated that the ownership of the company was compelled to use and develop MA techniques. First the government owned it and they did not practice MA. Then it was acquired by the Japanese management and for the first time they introduced the MA function to the organization. Subsequently, when the Netherlands management took over the management, they further developed MA techniques towards SMA. The study showed that Japanese and Netherlands managements are more concerned about the SMA techniques than government ownership. Similar findings have been made by Lachmann, et al. (2013) regarding the usage of SMA techniques in hospitals under competitive market environments. This study further elaborated that the nature and characteristics of management affect the usage of MA and SMA techniques. Because the Japanese management used more traditional MA techniques and SMA techniques based on cost and customer such as quality costing and customer analysis. The Netherlands management took initiative steps to introduce SMA techniques not only in cost perspective but also competitor perspective and 
performance perspective. The findings explain that Alpha widely uses quality costing, customer analysis, competitor position monitoring and competitor performance analysis on financial statements. The use of $\mathrm{ABC}$ and life cycle costing are at initial stage. But they are not familiar with target costing, value chain costing, and competitor cost analysis. Guilding et al. (2000) also mentioned competitor costing is the most popular practice in NZ, UK and USA. It is revealed that Alpha was not entitled with any generic strategy in early stages due to the monopolistic power they enjoyed. When competition was gradually increasing, they first moved to a cost leadership strategy and then shifted to differentiation strategy due to the vigorous competition and government controlling regulations. Wickramasinghe and Alawattage (2007) also mentioned that generic strategy is changing to align with changes in business environment, technology, competitors, regulations and global economy. The study suggested that there is a significant relationship between generic strategy and usage of SMA techniques (Shank, 1989; Shank \& Govindarajan, 1989; Lord, 1996; Cravens \& Guiding, 2001; Roslender \& Hart, 2002; Abdullah \& Said, 2015). Alpha practices traditional MA techniques on costing and SMA techniques in cost and customer perspective in the time period following cost leadership. Further, they have started to use SMA techniques in competitor perspective and performance perspective while they are practicing SMA techniques in cost perspective and customer perspective in the time period of differentiation strategy. Hence the study pointed out that when generic strategy is moved from cost leadership to differentiation, the adoptation rate of SMA practices also increases. (Chenhall \& Langfield-Smith, 1998; Cinquini \& Tenucci, 2010).

Table 3: Generic Strategy and SMA practices at Alpha

\begin{tabular}{llll}
\hline Time & Before 1997 & $1997-2007$ & 2008 to present \\
\hline Ownership & Fully Government & Government & Government 52\% \\
& & $65 \%$ & Netherlands 45\% \\
& & Japanese & Public 03\% \\
& & $35 \%$ & \\
Management & Government & Japanese & Netherlands \\
Competitive & None & High Cost & High \\
Advantage & & Leadership \& & Differentiation \& \\
& & Moderate & Low \\
& & Differentiation & Cost Leadership \\
SMA practices & None & Traditional MA & ABC (Initial stage) \\
& & Quality Costing & Life cycle costing \\
& & Customer Analysis & (Initial Stage) \\
& & Quality Costing \\
& & & (High usage) \\
\hline
\end{tabular}




\begin{tabular}{ll}
\hline Customer Analysis \\
(High Usage) \\
Competitor \\
position \\
monitoring (High \\
usage) \\
Competitor \\
performance \\
analysis on \\
financial \\
statements (high \\
usage) \\
BSC (Initial Stage) \\
\hline
\end{tabular}

Source: Interviews and survey data

\section{From the Lens of New Institutional Sociology (NIS) Theory}

The changes in SMA practices aligned with generic strategy in Alpha PLC are analyzed by referring to New Institutional Sociology Theory explained by DiMaggio and Powell (1983). Further, DiMaggio and Powell (1983) mentioned that the relationship between organizational practices and the society is elaborated in the process of isomorphism (A constraining process that forces one unit in a population to resemble other units that face the same set of environmental conditions). Hence, the SMA practice of Alpha PLC is identified to the isomorphism. Then, the three mechanisms (Coercive, Mimetic and Normative) for institutional isomorphic change are elaborated according to the context of Alpha PLC. DiMaggio and Powell (1983) have defined coercive pressure as the formal and informal pressures exerted on organizations from cultural expectations of the society and mimetic pressure is as the way organizations model themselves on other organizations to face uncertainty in the environment. According to them, normative pressure is the way organizations act like others in the field because of social and cultural pressures to establish occupational autonomy.

In the time period of Government Ownership, any coercive, mimetic and normative pressure for SMA practice was not visible as Alpha didn't practice MA as they had the monopolistic power in the telecommunications industry. However, there was a significant practice of MA and SMA under the period of Japanese Management. The coercive pressure came from shareholders and parent company influenced for executing cost leadership generic strategy in high scale and initiating MA practices in Alpha. Alpha is converted to a public limited company in Japanese management time period and shareholders were more concerned on cost reduction. 
Hence, Alpha adopted traditional MA techniques in its cost perspective. The quality costing technique was started in Alpha due the impact of parent company management as the Japanese management was highly interested in MA techniques in quality perspective because of the Japanese culture. Kapiyangoda and Gooneratne (2018) also pinpointed that coercive pressure from parent company affected management control systems by referring to its case study in a Sri Lankan company. Mimetic pressure from the competition was also evidenced in the Japanese management as the emerging competition in the industry focused to Alpha to adopt customer analysis technique to capture new customers and retain existing customers. Hopper and Major (2007) also showed coercive and mimetic factors affected the adoption of ABC by a Portuguese Telecommunications company.

The competition increased gradually in the Netherland's Management period. Cost leadership generic strategy shifted to Differentiation due to the vigorous competition in the industry and the government regulations on price strategies. These movements lead Alpha to shift from conventional MA to SMA practices. Further, the Netherlands management is more market centric. Hence, the coercive pressure from Netherland management and mimetic pressure from competition are effected high usage of Quality Costing, Customer Analysis, Competitor position monitoring and Competitor performance analysis on financial statements. Tsamenyi, Cullen and Gonzalez (2006) also found that coercive pressure from both regulatory environment and head office control affected the changes in the accounting and financial information system in Spain. Gamage and Gooneratne (2017) also claimed similar finding in an apparel firm in Sri Lanka. According to their study, coercive, normative and mimetic pressures impacted on management control changes.

\section{Conclusion}

The study was carried out to explore whether the change in generic strategy leads to changes in SMA practices in a telecommunications company in the Sri Lankan context. The findings are theoretically explained by referring to new institutional theory. The findings revealed that there is a significant relationship between cost leadership strategy and SMA techniques from the cost perspective. Further it elaborated that SMA techniques from competitor and customer perspectives are more practiced with differentiation strategy. According to institutional isomorphism, coercive and mimetic pressures affected the adaption of SMA practices in Alpha. The findings of the study contribute to development of literature in SMA as there is a lacuna in SMA literature (Nixon \& Burns, 2012). Further it generates valuable insights to SMA research studies in the Sri Lankan context as Langfield-Smith (2007) suggested conducting studies on practice of SMA 
techniques in specific organizational contexts. Further, it strongly contributes to using new institutional theory in MA. In practice, organizations can use SMA techniques to align with their generic strategy to gain competitive advantage. Further, the finding of the study will support the managers to use SMA techniques as a strategic management tool in the process of crafting strategies. The study creates opportunities for future studies to conduct a similar study in different industries and the same study by devising both qualitative and quantitative research methods.

\section{References}

Abdullah, N., \& Said, J. (2015). Enhancing the Governance of Government Linked Companies via Strategic Management Accounting Practices and Value Creation. Procedia Economics and Finance, 28, 222 - 229.

Arroyo, P. (2012). Management accounting change and sustainability: an institutional approach. Journal of Accounting \& Organizational Change, 8 (3), 286-309.

Alpha PLC Web. (2018). Alpha PLC Website. Retrieved 05, May, 2018, from https://www.Alpha.lk/dlg/about.

Braun, V., \& Clarke, V. (2013). Successful qualitative research: A practical guide for beginners. London: SAGE Publications.

Bromwich, M. (1990). The case for strategic management accounting: the role of accounting information for strategy in competitive markets. Accounting, Organizations and Society, 15 (1/2), 27-46.

Bromwich, M., \& Bhimani, A. (1994). Management Accounting Pathways to Progress, Chartered Institute of Management Accountants, London.

Brouthers, K., D., \& Roozen, F., A. (1999). Is it time to start thinking about strategic accounting?. Long Range Planning, 32, 311-22.

Burns, J., \& Scapens, R., W. (2000). Conceptualizing management accounting change: an institutional framework. Management accounting Research,11, 325 .

Cadez, S., \& Guilding, C. (2008). An exploratory investigation of an integrated contingency model of strategic management accounting. Accounting, Organizations and Society, 33(7/8), 836-63. 
Cadez, S., \& Gooneratne, T., N. (2016). Institutionalization of Activity Based Costing in a Sri Lankan Manufacturing Firm: A Case Study. Colombo Business Journal, 07(01).

Chenhall, R., H., \& Langfield-Smith, K. (1998). The relationship between strategic priorities management techniques and management accounting: an empirical investigation using a system approach. Accounting, Organizations and Society, 23 (3), 243-64.

Cinquini, L., \& Tenucci, A. (2010). Strategic management accounting and business strategy: a loose coupling?. Accounting \& Organizational Change, 6 (2), 228 259.

Cravens, K., S., \& Guilding, C. (2001). An empirical study of the application of strategic management accounting techniques. Advances in Management Accounting, 10, 95-124.

CIMA (2005) Official Terminology, London: CIMA publishing

Coad, A. (1996). Smart work and hard work: explicating a learning orientation in strategic management accounting. Management Accounting Research,7(4), 387408.

Cravens, K., S., \& Guilding, C. (2001). An empirical study of the application of strategic management accounting techniques. Advances in Management Accounting, 10, 95-124.

Denzin, N., K., \& Lincoln, Y., S. (2000). The Sage Handbook Of Qualitative Research (2nd ed.). Thousand Oaks, USA: SAGE Publications.

DiMaggio, P., J., \& Powell, W., W. (1983). The Iron Cage Revisited: Institutional Isomorphism and Collective Rationality in Organizational Fields, American Sociological Review, 48 (2), 147-160.

Gamage, S., D., D., \& Gooneratne, T. (2017). Management controls in an apparel group: an institutional theory perspective. Journal of Applied Accounting Research,18 (2), 223-241.

Gooneratne, T., N., \& Hoque, Z. (2016). Institutions, agency and the institutionalization of budgetary control in a hybrid state-owned entity. Critical Perspectives on Accounting, 36, 58-70.

Guilding, C. (1999). Competitor-focused accounting: an exploratory note. Accounting, Organizations and Society, 24, 583-595. 
Guilding, C., Cravens, K., S., \& Tayles, M. (2000). An international comparison of strategic management accounting practices. Management Accounting Research,11(1), 113-35.

Guilding, C., \& McManus, L. (2002). The incidence, perceived merit, and antecedents of customer accounting: an exploratory note. Accounting, organizations and society, 27, 45-59.

Hopper, T., \& Major, M. (2007). Extending institutional analysis through theoretical triangulation: regulation and activity-based costing in Portuguese telecommunications. European Accounting Review, 16 (1), 59-97.

Hoque, Z., \& Alam, M. (1999). TQM adoption, institutionalism and changes in management accounting systems: a case study, Accounting and Business Research, 29(3), 199-210.

Kapiyangoda, K., \& Gooneratne, T. (2018). Institutions, agency, culture and control: a case study of a multinational operating company. Journal of Accounting \& Organizational Change, 14 (4), 402-428.

Lachmann, M., Knauer, T., \& Trapp, R. (2013). Strategic management accounting practices in hospitals. Accounting \& Organizational Change, 9 (3), 336 - 369.

Langfield-Smith, K. (2008). Strategic management accounting: how far have we come in 25 years?. Accounting, Auditing \& Accountability Journal, 21 (2), 20428.

Lord, B. (1996). Strategic management accounting: the emperor's new clothes?. Management Accounting Research, 7 (3), 347-66.

McKinnon, J. (1988). Reliability and validity in field research: Some strategies and tactics. Accounting, Auditing and Accountability Journal, 1 (1), 34-54.

Meyer, J., W., \& Rowan, B. (1977). Institutionalized Organizations: Formal Structure as Myth and Ceremony. American Journal of Sociology, 83 (2), 340363.

Nixon, B., \& Burns, J. (2012a). The paradox of strategic management accounting. Management Accounting Research, 23, 229-244.

Nixon, B., \& Burns, J. (2012b). Editorial Strategic management accounting. Management Accounting Research, 23, 225- 228.

Porter, M. (1980). Competitive Strategy. The Free Press, New York. NY 
Porter, M. (1985). Competitive Advantage. The Free Press, New York, NY.

Rick wood, C., P., Coatest, J., B., \& Staceyt, R., J. (1990). Stapylton: strategic management accounting to gain competitive advantage. Management Accounting Research, 1, 37-49.

Roslender, R., and Hart, S., J. (2002). Integrating management accounting and marketing in the pursuit of competitive advantage: the case for strategic management accounting. Critical Perspectives on Accounting,13, 255-77.

Sharma, U., \& Hoque, Z. (2002). TQM implementation in a public sector entity in Fiji. International Journal of Public Sector Management, 15 (5), 340 - 360.

Shank, J., K. (1989). Strategic cost management: new wine, or just new bottles?. Journal of Management Accounting Research, 1, 47-65.

Shank, J., K., \& Govindarajan, V. (1989). Strategic Cost Analysis - The Evolution from Managerial to Strategic Accounting. Irwin, Homewood, IL.

Simons, R. (1990). The role of management control systems in creating competitive advantage: new perspectives. Accounting, Organizations and Society, 15(1/2), 127-43.

Simmonds, K. (1981). Strategic management accounting. Management Accounting, 59(4), 26-30.

Siti-Nabiha, A., K., \& Scapens, R., W. (2005). Stability and change: an institutionalist study of management accounting change. Accounting, Auditing \& Accountability Journal, 18 (1), 44-73.

Tillmann, K., \& Goddard, A. (2008). Strategic management accounting and sensemaking in a multinational company. Management Accounting Research, 19, 80-102.

Tsamenyi, M., Cullen, J., Mar ' '1a, J., \& Gonz ' alez ' , G. (2006). Changes in accounting and financial information system in a Spanish electricity company: A new institutional theory analysis. Management Accounting Research, 17, 409-432.

Telecommunications Regulatory Commission of Sri Lanka. (2017). Telecommunications Regulatory Commission of Sri Lanka Website. Retrieved 05, May, 2018 from http://www.trc.gov.lk/2014-05-13-03-56-46/statistics.html. 
Wickramasinghe, D., \& Alawattage. C. (2007). Management Accounting Change Approaches and perspectives, Routledge, New York.

Yin, R., K., (2009). Case Study research: Design and methods (4thed.). Thousand Oaks, USA: SAGE Publications.

Youssef, M., A. (2013). Management accounting change in an Egyptian organization: an institutional analysis. Journal of Accounting \& Organizational Change, 9 (1), 50-73. 